\title{
OBSERVATIONS ON THE CHLORIDE, SUGAR, AND CALCIUM CONTENTS OF THE CEREBRO-SPINAL FLUID IN CHILDREN.
}

\author{
BY
}

A. VICTOR NEALE, M.D., M.R.C.P., and MARION S. ESSLEMONT, B.Sc. (From the Children's Hospital, Birmingham.)

Examination of the cerebro-spinal fluid by the bio-chemical method is a relatively recent means of approach towards elucidation of accurate diagnosis, yet much has been written in support of, and against, its reliability. With the elaboration of more accurate methods it is, however, clear that an increasing value can be placed on the results obtained by this means.

The importance of any aid in differentiating the causes of the meningeal syndrome, which appears so frequently in children, is self-evident. The interpretation of bio-chemical results often requires more consideration in children than in adults. Thus the range of "normality" is greater in the child; probably the result of its more unstable organization. This point is well brought out by Donald Stewart ${ }^{1}$ in his paper on the normal cerebro-spinal fluid in children of various ages.

It is our intention in this paper to record some observations on the cerebrospinal fluid in sick children under the age of 12 years. We have considered more especially the chloride, sugar, and calcium contents of this fluid.

\section{I.-Chloride Content.}

\section{(a) In Non-meningitic Cases.}

The chloride content of cerebro-spinal fluid has been estimated in nonmeningitic cases, in children showing meningismus and in various forms of meningitis (Tables I-VI).

Table 1 shows the chloride content of the cerebro-spinal fluid as obtained by lumbar puncture in children who were suffering from some symptoms referable to the nervous system, but in none of whom was there any clinical or other evidence of inflammatory or other involvement of the meninges. The readings show a maximal and minimal figure of 783 and $696 \mathrm{mgrm}$. per cent. respectively, with a mean of 730 (Chart I).

No opportunity has been afforded us to carry out observations on healthy children, but it is of interest to compare these findings with Stewart's normal series. His figures show a considerable range in the chlorides, namely, 630 to 760 mgrm. per cent., with a mean of 728 , a value almost identical. with that 
obtained by us. Caffey, Maclean and Sullivan ${ }^{2}$ reported figures ranging from 675 to 750 in a series of normal children. We may therefore conclude, so far as our observations go, that these patients show no departure from the normal, the wide range being maintained. Further, from observations made on several of these patients it was found that, after a few days interval, a variation up to $40 \mathrm{mgrm}$. per cent. might occur in the same individual, this being in all probability related to changes in the blood chloride (vide infra).

(b) In Meningismus.

Table 2a shows the chloride content in the cerebro-spinal fluid in cases of pneumonia, during the febrile period of the illness. In each instance the chlorides are below 700 mgrm. per cent. This table should be contrasted with 
CHART I.

Non-Meningitic Cerebru-Spinal Fluids in Chifdren.

Chloridess and Sugars.

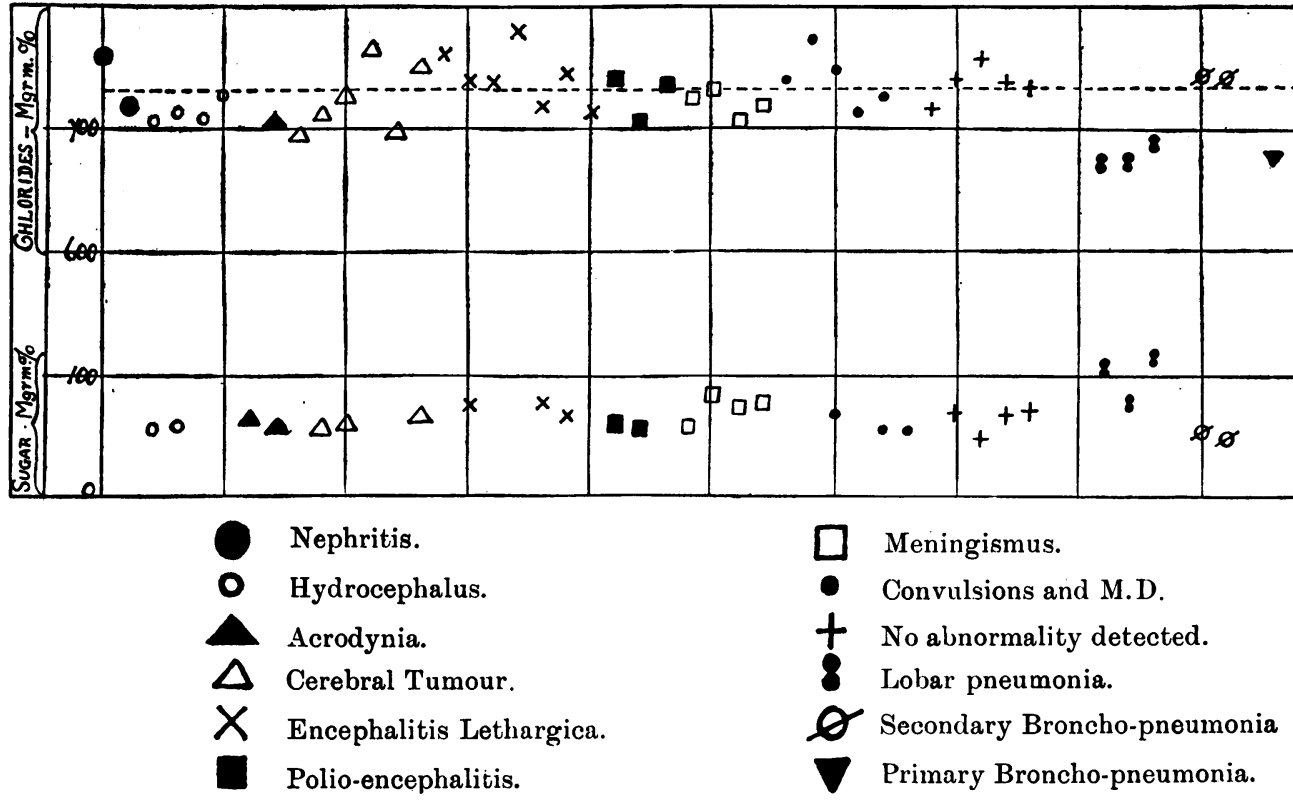

Table $2 \mathrm{~b}$ which gives the results obtained in cases showing meningismus but without any evidence of pneumococcal infection. In this group all the findings are above $700 \mathrm{mgrm}$. per cent. In view of the known disturbance of the body chlorides in acute pneumococcal disease it is of interest to note the lowering of the cerebro-spinal fluid chloride in this infection.

In none of the cases was there any abnormal cellular or bacterial content, and in the case of B.H. necropsy showed a complete absence of meningitis.

TABles 2A \& 2B. Chloride Content in Meningismus.

\begin{tabular}{|c|c|c|c|c|c|c|c|c|}
\hline Case. & Age. & \multicolumn{6}{|c|}{ Diagnosis. } & Chlorides. \\
\hline $\begin{array}{l}\text { A. } \\
\text { B.H. } \\
\text { S.S. } \\
\text { H.S. } \\
\text { S.S. } \\
\text { N.T. }\end{array}$ & $\begin{array}{c}6 / 12 \\
4 \\
9 \\
4 \\
7\end{array}$ & $\begin{array}{l}\text { Primary Broncho-pn } \\
\text { Lobar Pneumonia.. } \\
\text { Lobar Pneumonia.. } \\
\text { Lobar Pneumonia.. } \\
\text { Lobar Pneumonia.. }\end{array}$ & $\begin{array}{l}\text { nonia } \\
\ldots \\
\cdots \\
\cdots \\
\cdots\end{array}$ & $\begin{array}{l}\because \\
\cdots \\
\cdots \\
\cdots \\
\cdots\end{array}$ & $\begin{array}{l}\cdots \\
\cdots \\
\cdots \\
\cdots\end{array}$ & $\begin{array}{l}\cdots \\
\cdots \\
\cdots \\
\cdots\end{array}$ & $\begin{array}{l}\cdots \\
\cdots \\
\cdots \\
\cdots\end{array}$ & $\begin{array}{c}\text { mgrm. p.c. } \\
674 \\
670 \\
687 \\
673 \\
665\end{array}$ \\
\hline $\begin{array}{l}\text { B. } \\
\text { F.S. } \\
\text { K.P. } \\
\text { D.G. } \\
\text { L.M. }\end{array}$ & $\begin{array}{l}9 / 12 \\
2 \\
4 \\
7\end{array}$ & $\begin{array}{l}\text { Simple otitis media } \\
\text { Adenitis . . . } \\
\text { No definite disease } \\
\text { No definite disease }\end{array}$ & $\begin{array}{l}\cdots \\
\cdots \\
\cdots \\
\cdots\end{array}$ & $\begin{array}{l}\cdots \\
\cdots \\
\cdots \\
\cdots\end{array}$ & $\begin{array}{l}\cdots \\
\cdots \\
\cdots \\
\cdots\end{array}$ & $\begin{array}{l}\cdots \\
\cdots \\
\cdots \\
\cdots\end{array}$ & $\begin{array}{l}\cdots \\
\cdots \\
\cdots \\
\cdots\end{array}$ & $\begin{array}{l}725 \\
720 \\
747 \\
720\end{array}$ \\
\hline
\end{tabular}


(c) In Tuberculous Meningitis.

Table 3 shows the chloride content of the cerebro-spinal fluid in specimens obtained on admission of the children into the hospital. The readings range from a maximum of 673 to a minimum of $500 \mathrm{mgm}$. per cent., thus giving a mean of $613 \mathrm{mgm}$. per cent., but two cases (A. S. and K. W.) show unusually high figures. These findings, it should be stressed, give the condition directly after admission of the.child to hospital and are not related to the stage of the illness. Some months ago we had an opportunity to examine specimens of cerebro-spinal fluid during the course of a case of tuberculous meningitis. On plotting out a curve of the results obtained it was seen that a descent occurred in the earlier stages of the disease and an ascent in the later stages. Similar observations have since been made in ten other cases. The diagnosis in each of the cases studied was confirmed at necropsy. The results are shown in Chart II. Each curve shows a different level on the Chart, but the type of curve is the same in all cases and is uninfluenced by the course of the illness, whether this be a rapid or relatively slow one. The maximum figure on the Chart is 802 and the minimum is 493 : the former being a reading obtained in a case in the terminal stage of the illness, and the latter an earlier phase in another case. As a result of single observations in cases of meningitis, various workers have stated that the chloride in cerebro-spinal fluid in tuberculous meningitis is invariably at a low level. This statement is incorrect. Thus some of our cases (e.g., A. S., K. W., and H. H.) have readings, taken throughout the iliness, within normal levels. The results we have obtained show, 
CHART II.

Tuberculous Mexingitis in Children.

Chloride Curves plotted backwards. From Death Point.

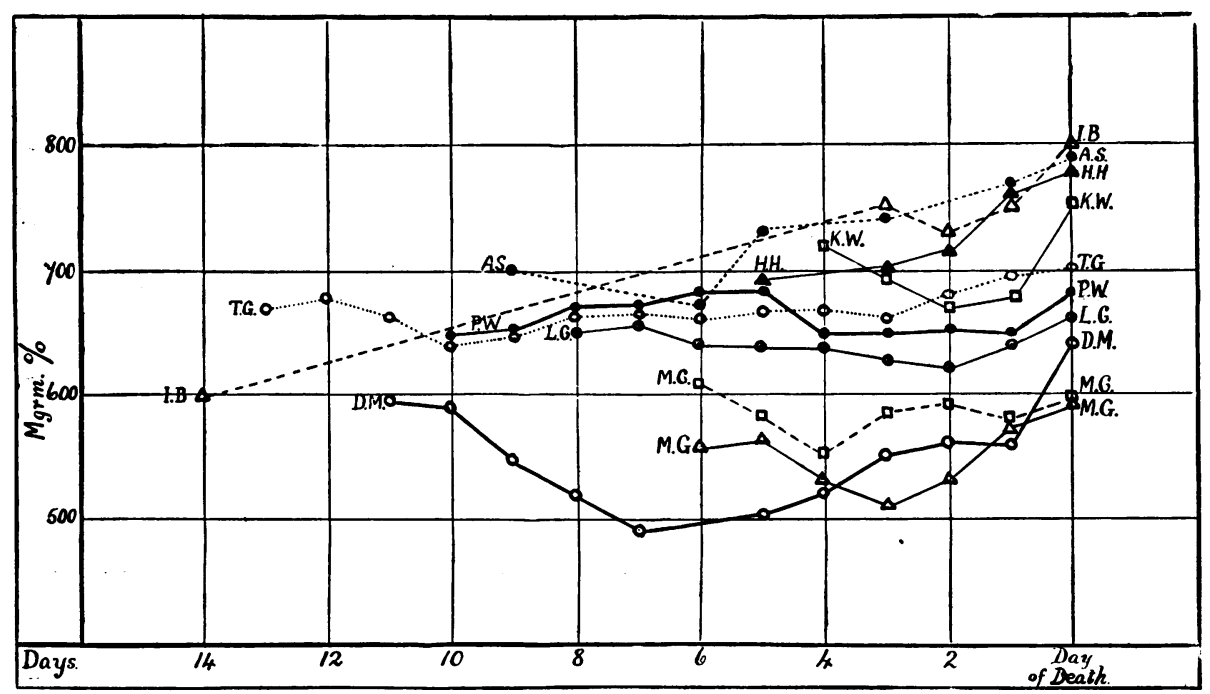

therefore, that although it is common to obtain a subnormal chloride figure in tuberculous meningitis, this is not always the case, and also that it is necessary to take into account the stage of the illness.

table 4. Chloride Content in Pneumococcal Meningitis.

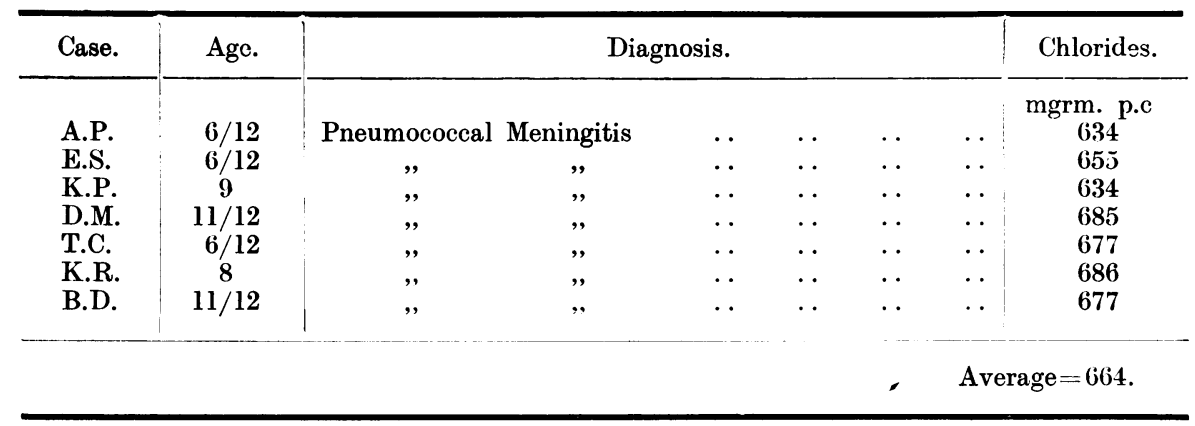

(d) In Pneumococcal Meningitis.

This series of single observations, taken on admission of the patient to hospital, shows a comparatively low reading, although not so low as the average of the tuberculous cases.

Plotting the results of examinations (Chart III) made during the course of the illness, shows a fairly characteristic curve, there being, with one exceptional case, a continuous descent until the fatal issue. The exception was obtained from a patient (K. P.) who showed unusual clinical features and a correspondingly interesting curve. On admission he presented the typical appearance of meningitis and had a slightly purulent cerebro-spinal fluid. Several days later a remarkable improvement in his general condition occurred 
CHART III.

Pneumococcal Meningitis in Children.

Chloride Curves plotted backwards from Death Puint.

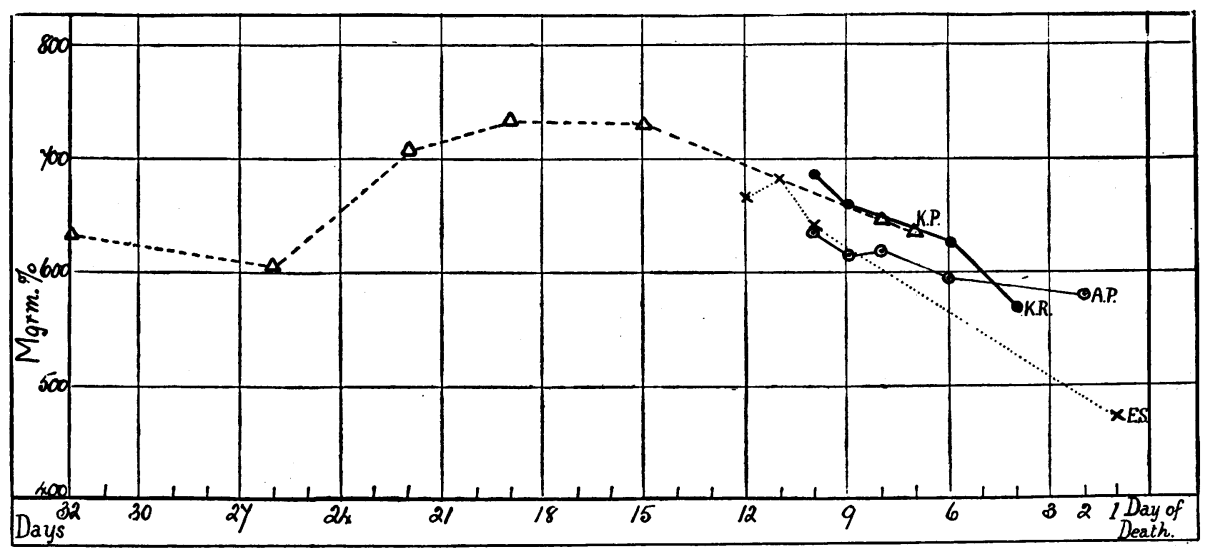

and the cerebro-spinal fluid pressure decreased. Synchronously with this the cerebro-spinal fluid became almost clear and the chloride (and sugar) content showed a rise towards the normal limit. This state of affairs continued for nine days, when a sudden relapse occurred with the reappearance of a purulent cerebro-spinal fluid, there being also a fall in the chloride corresponding with the grave condition. The fluid became increasingly purulent and the chloride content continued to diminish until the patient died.

The average of readings obtained in the final specimens in the cases of pneumococcal meningitis is 557, a figure much lower than that found in the final specimens in tuberculous meningitis, which was 692. This is interesting since it is the opposite of that found for the average of readings of the earliest specimens.

TABle 5. Chloride Content in Meningococcal Meningitis.

\begin{tabular}{|c|c|c|c|c|c|c|c|c|}
\hline Case. & Age. & & Diag & & & & & Chlorides. \\
\hline $\begin{array}{l}\text { J.H. } \\
\text { M.B. } \\
\text { M.G. } \\
\text { A.C. } \\
\text { C.W. } \\
\text { B.D. }\end{array}$ & $\begin{array}{c}10 \\
11 / 12 \\
2 \frac{1}{2} \\
4 / 12 \\
3 / 12 \\
11 / 12\end{array}$ & $\begin{array}{c}\text { Meningococcal } \\
\text { " } \\
\# \\
,\end{array}$ & $\begin{array}{c}\text { Meningitis } \\
\text { " } \\
\text { " } \\
\text { " }\end{array}$ & $\begin{array}{l}. . \\
\cdots \\
\cdots \\
\cdots \\
. .\end{array}$ & $\begin{array}{l}. \\
. \\
. \\
. \\
.\end{array}$ & $\begin{array}{l}. . \\
\because \\
\because \\
\because \\
.\end{array}$ & \begin{tabular}{l|l}
. & \\
. & \\
. & \\
. & \\
. & \\
.. &
\end{tabular} & $\begin{array}{c}\text { mgrm. } \\
644 \\
706 \\
657 \\
615 \\
689 \\
677\end{array}$ \\
\hline
\end{tabular}

Average $=664$.

(e) In Meningococcal Meningitis.

Single observations made when the patients were first admitted to hospital (Table 5) show a fairly considerable variation, with a subnormal mean. Curves of serial examinations indicate, however, that the figures must be correlated with the stage of the illness and the progress of the case. Chart IV shows curves in two children (J. H. and M. G.) who recovered and in two (A. C. and C. W:) 
CHART IV.

Meningocuccal Meningitis in Children.

Chlorides.

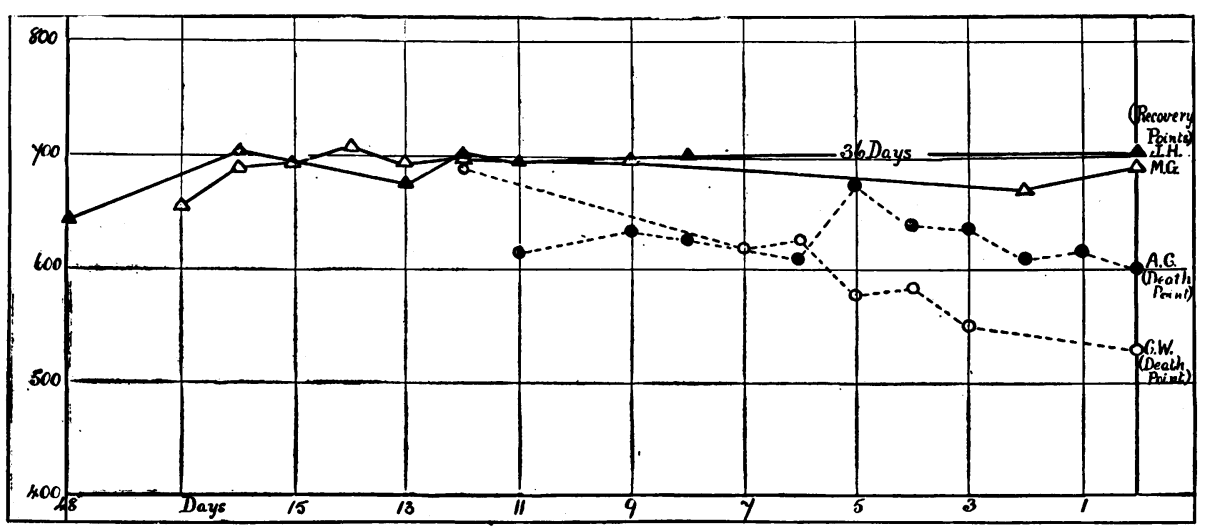

who died. The former show a steady rise towards normal ; the latter a steady fall as the case approaches an end, giving a terminal mean of 696 in the recovered and 564 in the fatal cases.

\section{Chloride in Cerebro-spinal Fluid and Blood.}

Linder and Carmichael ${ }^{3}$ have suggested that the fall in the chloride of the cerebro-spinal fluid is dependent upon a similar decrease in the chloride in the blood, and that the relative concentration of chloride in the two fluids always remains the same. We have therefore estimated the chloride in specimens of blood and cerebro-spinal fluid taken simultaneously. The results, when more than one estimation was made during the course of the case are shown in Table 6 ; and Chart $\mathrm{V}$ shows the results in 26 cases in which only one estimation of each was performed. In all instances the chloride was estimated in the whole blood.

CHART V.

Chart Showini Relationship of C.S. Fluid and Biood Chlorides.

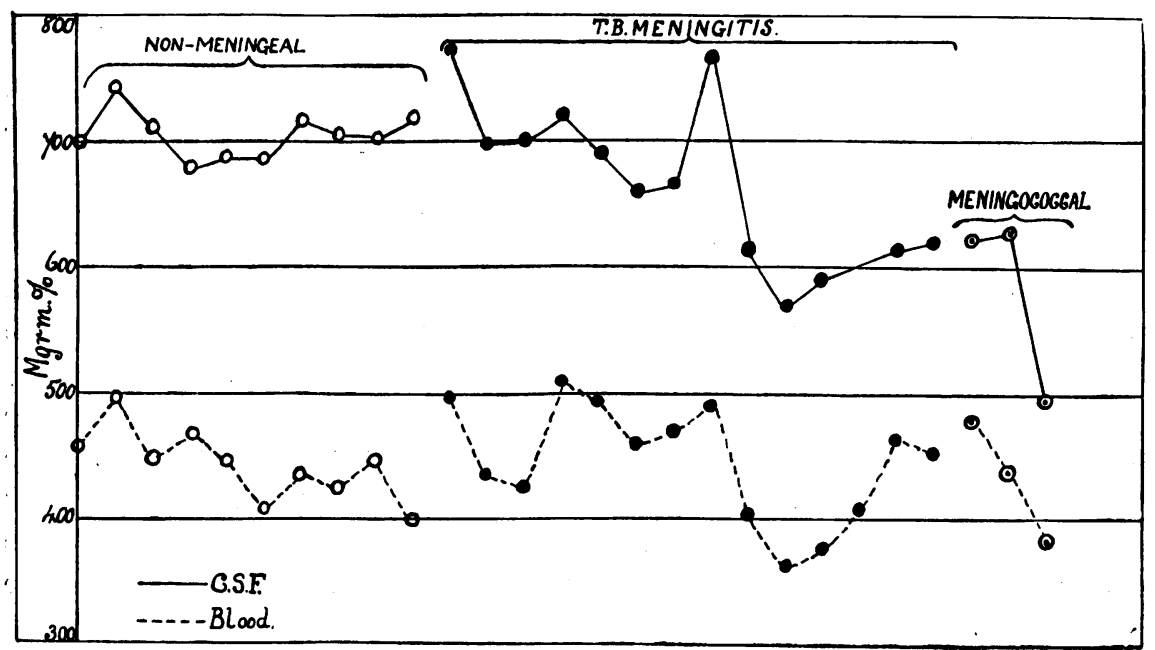


table 6. Chloride in Cerebro-Spinal Fluid and Blood.

\begin{tabular}{|c|c|c|c|c|c|c|c|}
\hline \multirow{2}{*}{ Case. } & \multirow{2}{*}{ Age. } & \multirow{2}{*}{\multicolumn{2}{|c|}{ Diagnosis. }} & & & \multicolumn{2}{|c|}{ Chlorides, mgrm. per cent. } \\
\hline & & & & & & C.S.F. & Blood. \\
\hline $\begin{array}{l}\text { D.C. } \\
\text {," } \\
\text { ". } \\
\text { H.S. } \\
\text {," }\end{array}$ & $\begin{array}{l}4 / 12 \\
\dddot{ } \\
\dddot{9} \\
\dddot{9}\end{array}$ & $\begin{array}{c}\text { Encephaliti } \\
\text { ", } \\
\text { Pneumonia } \\
\text {," }\end{array}$ & $\begin{array}{c}\text { Lethargica } \\
\text { ", } \\
\text { and Meningismus }\end{array}$ & $\begin{array}{l}\ldots \\
\cdots \\
\cdots \\
\cdots \\
\ldots\end{array}$ & $\begin{array}{l}\cdots \\
\cdots \\
\cdots \\
\cdots \\
\cdots\end{array}$ & $\begin{array}{l}741 \\
711 \\
678 \\
687 \\
687 \\
718\end{array}$ & $\begin{array}{l}495 \\
443 \\
467 \\
443 \\
408 \\
433\end{array}$ \\
\hline $\begin{array}{c}\text { K.W. } \\
\text { " } \\
\text { " } \\
\text { M.C. } \\
\text { ", }\end{array}$ & $\begin{array}{l}2 \\
\text { " } \\
\text { " } \\
\text { 2 } \\
\text { " }\end{array}$ & $\begin{array}{c}\text { Tuberculous } \\
\text { ", } \\
\text { ", } \\
\text { ", }\end{array}$ & $\begin{array}{c}\text { Meningitis } \\
\text { ", } \\
\text { " } \\
\text { " } \\
\text { ", }\end{array}$ & $\begin{array}{l}\ldots \\
\cdots \\
\cdots \\
\cdots \\
\cdots \\
\cdots\end{array}$ & $\begin{array}{l}\ldots \\
\cdots \\
\cdots \\
\cdots \\
\cdots \\
\cdots \\
\cdots\end{array}$ & $\begin{array}{l}720 \\
689 \\
660 \\
664 \\
763 \\
615 \\
569 \\
589\end{array}$ & $\begin{array}{l}510 \\
492 \\
457 \\
467 \\
488 \\
401 \\
359 \\
373\end{array}$ \\
\hline $\begin{array}{c}\text { C.W. } \\
" \\
"\end{array}$ & $\begin{array}{l}" \\
\text { " }\end{array}$ & $\begin{array}{l}\text { " } \\
\text { ", }\end{array}$ & ", & $\begin{array}{l}\because \\
\cdots \\
.\end{array}$ & $\begin{array}{l}\ddot{.} \\
\cdots\end{array}$ & $\begin{array}{l}620 \\
626 \\
489\end{array}$ & $\begin{array}{l}476 \\
436 \\
380\end{array}$ \\
\hline
\end{tabular}

The Charts show that when both fluids are examined at the same time there is a general agreement between their relative chloride contents, but no strict ratio could be established. This agreement is manifest both in children suffering from meningitis and in those in which meningitis is not present, and indeed, so far as our figures go, appears to be more in evidence in the meningitic cases.

\section{II.-Sugar Content.}

\section{(a) In Non-Meningitic Cases.}

As in the chloride studies, it has not been possible to carry out a series of observations on healthy children, but the cerebro-spinal fluid sugar was estimated in a number of children who showed no evidence of meningitis. The results are sent forth in Table 7 and in Chart $I$.

Table 7 shows the findings in 24 cases. The cellular content was in each case normal. Stewart's series of normal children gives an extreme range of 27 to 84 mgrm. per cent., but the majority showed a figure between 45 and 70 . It will be seen that our results, as in the chloride series, show a close resemblance to those obtained by Stewart.

\section{(b) In Tuberculous Meningitis.}

The estimations of the sugar content, like those of the chlorides, have been made on fresh specimens of cerebro-spinal fluid obtained serially during the course of the disease, and the findings are shown in Chart VI.

In most instances a curve having somewhat similar features to the chloride curve is obtained, in other words an early fall followed later by a rise. The maximum and minimum range is 72 and 0 respectively. It is noteworthy that in one patient (K. W.) a total absence of sugar occurred throughout the period of observation, and in four cases zero point was reached at one stage of the illness. 
table 7. Sugar Content of Cerebro-Spinal Fluid.

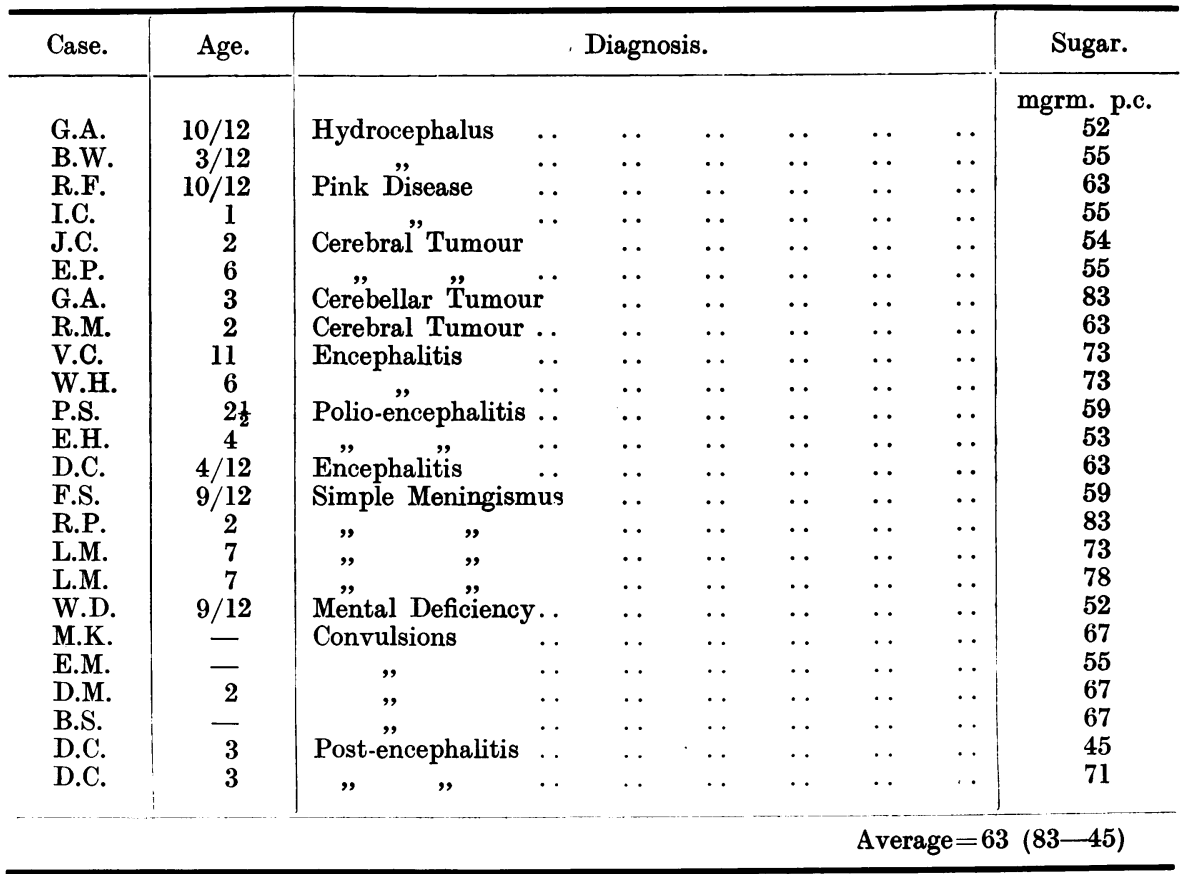

\section{ICHART VI.}

Tuberculous Meningitis in Children.

Sugar Curves plotted backwards from Deati Point.

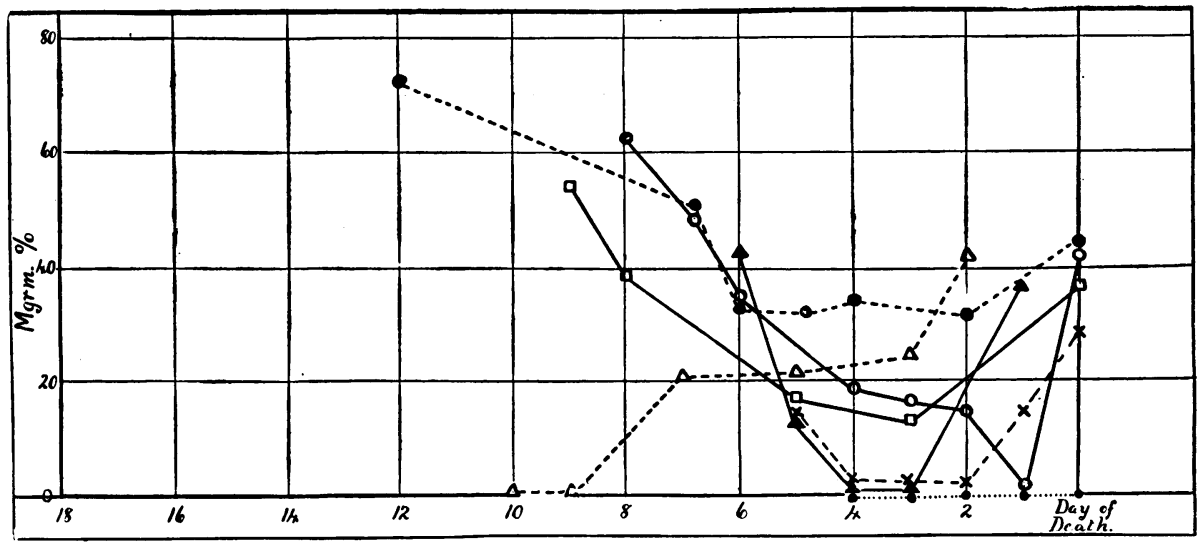

The results once more demonstrate that the wide range in the readings must be correlated with the particular case and with the stage of the illness, and that a fallacy may arise in making a diagnosis from a single reading.

(c) In Meningococcal Meningitis.

Four cases, two being fatal, were investigated, and the results are shown in graph form (Chart VII). 
The cases which recovered showed an initial low reading, with some fluctuation from day to day until the stage of recovery was reached, when an elevation of the sugar content to the normal occurred. In neither case was zero point reached. On the other hand in each of the two fatal cases the sugar content fell to zero and remained low throughout the illness, but of these, one showed a slight rise in the moribund phase.

Caffey, Maclean and Sullivan ${ }^{2}$ also found that in children recovery occurred with the return of the sugar content in the cerebro-spinal fluid to normal. This improvement might, however, be delayed for fourteen days. They showed that in uncomplicated cases anti-serum itself did not cause any rise in the cerebro-spinal fluid sugar.

Occasionally, in fatal cases, a terminal increase in the cerebro-spinal fluid sugar is associated with terminal hyperglycæmia and glycosuria.

\section{CHART VII.}

Meningococcal Meningitis in Children.

Sugars.

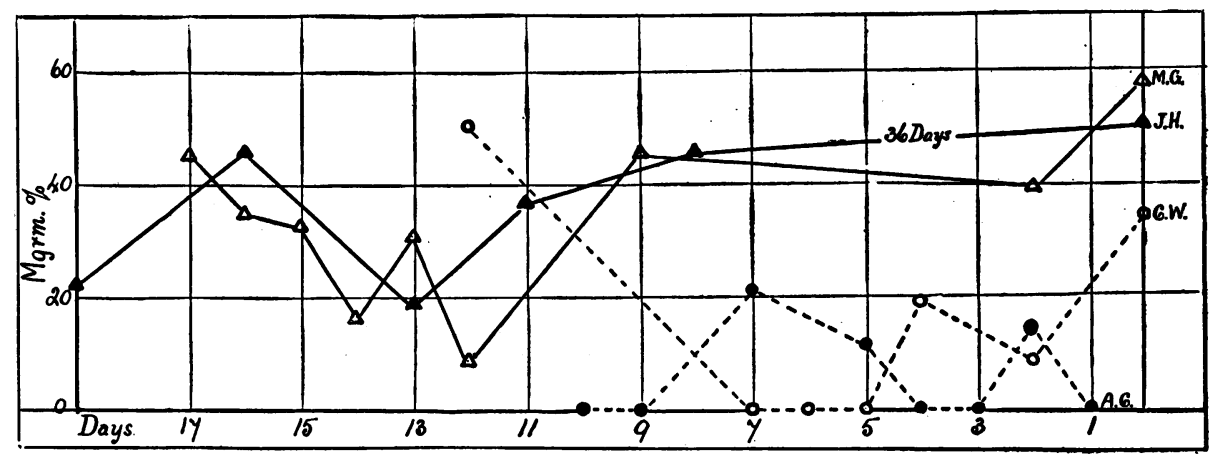

M.G. and J.H. recovered. C.W. and A.C. died.

\section{(d) In Pneumococcal Meningitis.}

Four cases of this variety of meningitis were also investigated. All show low readings and in one case sugar was constantly absent (Chart VIII).

The case of $K$. P., to which reference has already been made, shows an interesting sugar curve which corresponds with the chloride curve. There is the initial fall followed by a rise to the normal zone associated with a remarkable improvement in the general features of the case, and the second fall occurring with a sudden and rapid deterioration.

\section{III.-Calcium Content.}

Halverson and Bergeim ${ }^{4}$ and several other investigators, have found that the calcium content of the cerebro-spinal fluid in the normal person is fairly constant, namely, about $5 \mathrm{mgrm}$. per cent., and that it is equivalent to about a half of the calcium content of the blood plasma. Repeated drainage of the subarachnoid space has been found not to change the calcium content. Leicher ${ }^{5}$ in 29 cases found the average amount of calcium in the cerebro-spinal 
fluid to be about $5 \mathrm{mgrm}$. per cent., and that this figure was unaffected by variations in the pressure of the cerebro-spinal fluid. More recent methods have shown a normal figure slightly higher, namely, 5.5 mgrm. per cent.

We have estimated the calcium content in children suffering from meningitis and in children with other diseases. In both groups we have included children who had convulsions and those whose illness was not characterised by this sign. No cases showing the phenomena of tetany are included.

According to our results which are given in Table 8 and in Chart IX, it is shown that, in patients having neither convulsions nor evidence of meningeal involvement, the calcium content of the cerebro-spinal fluid was found to vary from $5 \cdot 1$ to $6.5 \mathrm{mgrm}$. per cent. A comparable series of examinations in cases of meningitis without convulsions shows, on the whole, slightly higher figures. Further, in children suffering from meningitis with convulsions there is a still

CHART VIII.

Pneumococcal Meningitis in Children,

Sugar Curves plotted backwards from Death Point.

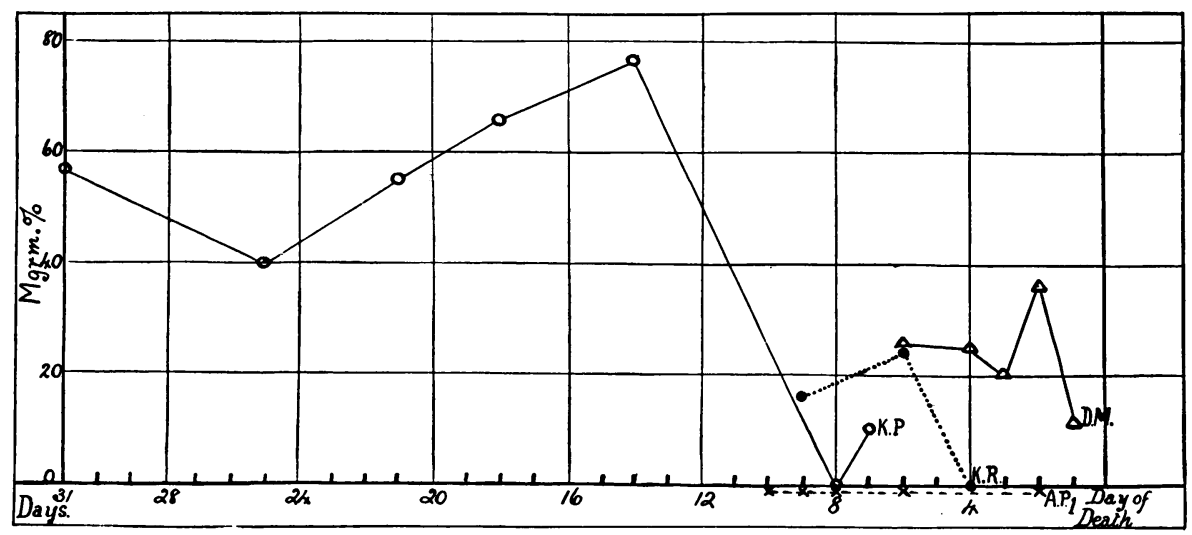

greater increase in the individual and average readings. This investigation was made primarily to determine whether there was any difference between the calcium content in convulsive as compared with non-convulsive conditions. By analogy with tetany and some other neurogenic disorders, it was thought that possibly a diminution in the calcium in the cerebro-spinal fluid circulating in the subarachnoid space might be a determining factor in the genesis of convulsions in meningitis. Our results, however, do not support the hypothesis ; on the contrary, with the meningeal involvement there is almost always a rise in the calcium above the normal, and this is even more marked in the presence of convulsions.

The mean readings in the different groups are as follows:-

(a) Non-meningitic cases (no convulsions) $5.6 \mathrm{mgrm}$. per cent.

(b) " " " (with ", ) $5 \cdot 7$ " , ,

(c) Meningitic cases (no ", ) 6.3 ", ", ",

(d) , " (with,$\quad$ ) $6.8 \%, "$, 
Table 8. Calcium Content in the Cerebro-Spinal Fluid.

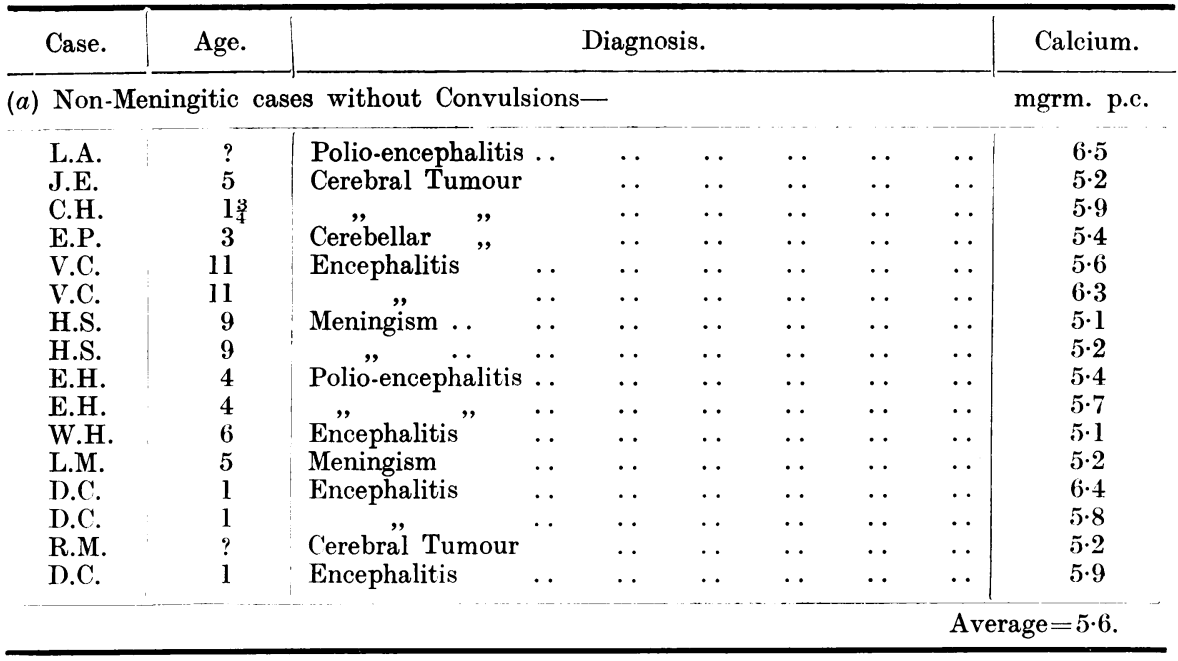

(b) Non-Meningitic cases with Convulsions :-

\begin{tabular}{ll|llllllll|l} 
M.G. & $\vdots$ & Epilepsy & $\ldots$ & $\ldots$ & $\ldots$ & $\ldots$ & $\ldots$ & $\ldots$ & $\ldots$ & $5 \cdot 8$ \\
B. & 1 & Measles & $\ldots$ & $\ldots$ & $\ldots$ & $\ldots$ & $\ldots$ & $\ldots$ & $\ldots$ & $6 \cdot 1$ \\
E.M. & 4 & Epilepsy & $\ldots$ & $\ldots$ & $\ldots$ & $\ldots$ & $\ldots$ & $\ldots$ & $\ldots$ & $5 \cdot 3$ \\
\hline
\end{tabular}

(c) Tuberculous Meningitis without Convulsions :-

\begin{tabular}{|c|c|c|c|c|c|c|c|c|c|}
\hline L.T. & 8 & Tuberculous & Meningitis & . & . & . & .. & $\ldots$ & $6 \cdot 1$ \\
\hline C.S. & $1 \frac{1}{2}$ & , &, & . & . & . & . & $\ldots$ & $6 \cdot 8$ \\
\hline K.W. & 2 & ," & , & . & . & . & . & $\ldots$ & $6 \cdot 3$ \\
\hline K.W. & 2 & , & , & . & . & . & . & $\ldots$ & $6 \cdot 5$ \\
\hline K.W. & 2 & , & , & . & $\cdots$ & . & . & $\ldots$ & $6 \cdot 3$ \\
\hline M.C. & 2 & , & ", & . & . & . & . & $\ldots$ & $5 \cdot 7$ \\
\hline M.C. & 2 & , & , & . & . & . & . & . & $5 \cdot 8$ \\
\hline M.C. & 2 & , & ," & . & . & . & . & $\ldots$ & $6 \cdot 0$ \\
\hline M.C. & 2 & , & , & . & . & . & .. & . & 6.5 \\
\hline M.C. & 2 & , & , & . & . & . & . & . & $6 \cdot 6$ \\
\hline M.C. & 2 & , & , & . & . & . & . & . & $6 \cdot 3$ \\
\hline M.C. & 2 & ," & ," & $\ldots$ & $\ldots$ & $\ldots$ & $\ldots$ & $\ldots$ & $6 \cdot 1$ \\
\hline A.C. & 9 & , & , & . & . & . & . & $\ldots$ & $6 \cdot 1$ \\
\hline A.C. & 9 & , &, & $\ldots$ & . . & $\ldots$ & . & $\ldots$ & $5 \cdot 7$ \\
\hline A.C. & 9 & , & , & . & . & . & . & . & $5 \cdot 6$ \\
\hline
\end{tabular}

(d) Tuberculous Meningitis with Convulsions :-

\begin{tabular}{|c|c|c|c|c|c|c|c|c|c|}
\hline F.J. & $4 / 12$ & Tuberculous & Meningitis & $\ldots$ & $\ldots$ & . & $\ldots$ & $\ldots$ & $7 \cdot 1$ \\
\hline J.H. & $3 / 12$ & , & ,, & . & .. & . & . & . & $5 \cdot 9$ \\
\hline A.S. & $9 / 12$ & , & , & $\ldots$ & . & . & . & . & $7 \cdot 3$ \\
\hline S.T. & 13 & , & , & . & . & . & . & .. & $6 \cdot 5$ \\
\hline L.C. & $6 / 12$ & , & , & & . & . & . & . & $6 \cdot 8$ \\
\hline L.C. & $6 / 12$ &, & , & . & . & . & . & . & $6 \cdot 7$ \\
\hline I.C. & $6 / 12$ & ", & ," & . & . & . & . & . & $6 \cdot 4$ \\
\hline L.C. & $6 / 12$ & , & , & $\ldots$ & $\ldots$ & . & . & .. & $7 \cdot 4$ \\
\hline L.C. & $6 / 12$ & , & , & . & . & . & . & . & $8 \cdot 0$ \\
\hline I.B. & $8 / 52$ & , & , & . & . & . & . & .. & $7 \cdot 8$ \\
\hline I.B. & $8 / 52$ & , & , & . & $\cdots$ & . & . & . & $7 \cdot 3$ \\
\hline I.B. & $8 / 52$ & ," & ,, & . & . & . & . & . & $6 \cdot 9$ \\
\hline I.B. & $8 / 52$ & , & , & . & .. & . & . & . . & $6 \cdot 7$ \\
\hline \multirow[t]{2}{*}{ K.C. } & 1 & , & , & . & . & . & $\cdots$ & . & $4 \cdot 8$ \\
\hline & & & & & & & & \multicolumn{2}{|c|}{ Average $=6 \cdot 8$} \\
\hline
\end{tabular}


(e) Meningococcal Meningitis (with Convulsions) :-

\begin{tabular}{|c|c|c|c|c|c|c|c|c|}
\hline $\begin{array}{l}\text { A.C. } \\
\text { A.C. } \\
\text { A.C. } \\
\text { A.C. } \\
\text { A.C. } \\
\text { A.C. } \\
\text { A.C. } \\
\text { A.C. } \\
\text { A.C. }\end{array}$ & $\begin{array}{l}4 / 12 \\
4 / 12 \\
4 / 12 \\
4 / 12 \\
4 / 12 \\
4 / 12 \\
4 / 12 \\
4 / 12 \\
4 / 12\end{array}$ & $\begin{array}{c}\text { Meningococcal } \\
\text { " } \\
\text { " } \\
\text { " } \\
\text { " } \\
\text { " }\end{array}$ & $\begin{array}{c}\text { Meningitis } \\
\text {," } \\
\text { " } \\
\text { ", } \\
\text { " } \\
\text {, }\end{array}$ & $\begin{array}{l}\ldots \\
\ldots \\
\ldots \\
\ldots \\
\cdots \\
\ldots \\
\ldots\end{array}$ & $\begin{array}{l}\ldots \\
\ldots \\
\ldots \\
\cdots \\
\cdots \\
\ldots \\
\cdots\end{array}$ & $\begin{array}{l}\ldots \\
\ldots \\
\ldots \\
\ldots \\
\cdots \\
\ldots \\
\cdots \\
\ldots\end{array}$ & $\begin{array}{l}\ldots \\
\ldots \\
\ldots \\
\ldots \\
\cdots \\
\ldots \\
\ldots\end{array}$ & $\begin{array}{r}7 \cdot 4 \\
7 \cdot 2 \\
9 \cdot 5 \\
7 \cdot 0 \\
7 \cdot 4 \\
7 \cdot 7 \\
7 \cdot 3 \\
10 \cdot 0 \\
7 \cdot 7\end{array}$ \\
\hline & & & & & & & \multicolumn{2}{|c|}{ Average $=7.9$} \\
\hline
\end{tabular}

(f) Meningococcal Meningitis (without Convulsions) :-

\begin{tabular}{|c|c|c|c|c|c|c|c|c|}
\hline $\begin{array}{l}\text { C.W. } \\
\text { C.W. } \\
\text { C.W. } \\
\text { C.W. } \\
\text { C.W. }\end{array}$ & $\begin{array}{l}3 / 12 \\
3 / 12 \\
3 / 12 \\
3 / 12 \\
3 / 12\end{array}$ & $\begin{array}{c}\text { Meningococcal } \\
\text {, } \\
\text { ", } \\
\text { ", }\end{array}$ & $\begin{array}{c}\text { Meningitis } \\
\text { ", } \\
\text { ", }\end{array}$ & $\begin{array}{l}\cdots \\
\cdots \\
\cdots \\
\cdots\end{array}$ & $\begin{array}{l}\ldots \\
\cdots \\
\cdots \\
\cdots\end{array}$ & $\begin{array}{l}\cdots \\
\cdots \\
\cdots \\
\cdots\end{array}$ & $\begin{array}{l}\ldots \\
\ldots \\
\cdots \\
\ldots \\
\cdots\end{array}$ & $\begin{array}{l}7 \cdot 0 \\
6 \cdot 9 \\
7 \cdot 0 \\
6 \cdot 8 \\
6 \cdot 9\end{array}$ \\
\hline & & & & & & & \multicolumn{2}{|c|}{ Average $=6.9$} \\
\hline
\end{tabular}

CHART IX.

Calcium in the Cerebro-Spinal. Fluid.

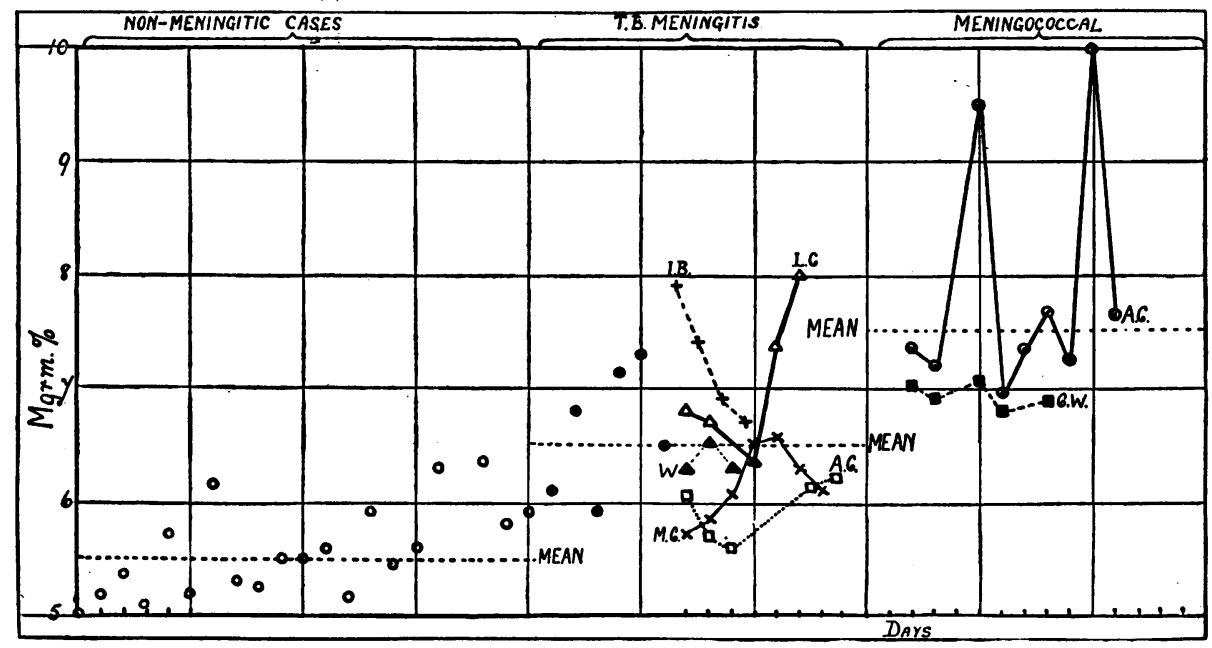

\section{ConcLusions.}

1. The sugar, chloride and calcium contents of the cerebro-spinal fluid of children suffering from various diseases without meningeal involvement are within normal limits, with the exception that in acute pneumococcal infection a subnormal chloride content is present.

2. The current view that tuberculous meningitis is constantly associated with a low chloride content in the cerebro-spinal fluid is criticised. The necessity for considering the stage of the illness when reading bio-chemical results is indicated, 
3. Comparisons are drawn between the chloride content in tuberculous meningitis and other forms of meningitis. When examinations are made at frequent intervals during the course of the illness, curves of the results show special features in each kind of disease. The tuberculous cases show a fall in the earlier stages and a rise in the later stages. Pneumococcal cases show a progressive fall towards the fatal issue. Meningococcal cases show the same in fatal cases but recovering cases show an elevation to within the normal.

4. The sugar curve in tuberculous meningitis is similar to the chloride curve in the same cases. A fall to zero point may occur during the illness and occasionally remain until death.

5. In fatal meningococcal meningitis and in pneumococcal meningitis a progressive diminution in the sugar content of the cerebro-spinal fluid occurs.

6. The sugar in the cerebro-spinal fluid in recoverable meningococcal cases shows an early fall followed by a gradual rise to normal. Therefore a sugar curve which commences to rise is of favourable prognostic import.

7. Evidence is given supporting the view that in non-meningitic and meningitic cases, the amount of chloride in the cerebro-spinal fluid varies to some degree with that in the blood.

8. A number of observations have been made on the calcium in the cerebrospinal fluid. In non-meningitic disease it is shown that the calcium concentration is within the normal. Also that in conditions where inflammatory change occurs in the meninges the calcium is usually above the normal level, and this is more marked in the suppurative types of meningitis.

9. No calcium deficiency was detected in patients having convulsive seizures in meningitis.

We wish to express our thanks to Dr. Leonard G. Parsons, physician to the hospital and Dr. Evelyn Hickmans, bio-chemist, for their help and criticism; also to the Medical Research Council for defraying part of the expenses.

The bio-chemical methods used in this investigation were :-

(a) For cerebro-spinal fluid chloride: Whitehorn, Journal of Biological Chemistry, 1921, Vol. 46, page 450. Using $1 \mathrm{c.cm}$. of cerebro-spinal fluid.

(b) For cerebro-spinal fluid sugar: Maclean's Blood Sugar Method, using $0.4 \mathrm{c.cm}$. of cerebro-spinal fluid. Bio-chemical Journal, 1919, Vol. XIII, page 135. Each estimation was made within an hour of obtaining the specimen.

(c) For cerebro-spinal fluid calcium : Kramer and Tisdall (modified by Tisdall) using $4 \mathrm{c.cm}$. cerebro-spinal fluid. Journal of Biological Chemistry, 1923, Vol. 56, page 439.

\section{REFERENCES.}

1. Stewart, D., Arch. Dis. Child., Lond., 1928, III, 96.

2. Caffey, Maclean and Sullivan, J. Am. Med. Asse, Chic., 1927, LXXXVIII.

3. Linder and Carmichael, Biochem. J., Camb., 1928, XXII, 46.

4. Halverson and Bergeim, Research Publications, R. Soc. Med,

5. Leicher, ibid. 